\title{
Has implementation of Local Air Quality Management reduced local nitrogen dioxide concentrations in the UK?
}

\author{
J. H. Barnes, E. T. Hayes \& J. W. S. Longhurst \\ Air Quality Management Resource Centre, \\ University of the West of England, UK
}

\begin{abstract}
In February 2014 the European Commission launched legal proceedings against the UK for its failure to cut excessive levels of nitrogen dioxide $\left(\mathrm{NO}_{2}\right)$. The failure of national action to achieve the necessary reduction in $\mathrm{NO}_{2}$ places an increasing onus on local authorities in the UK to assist the government with the achievement of the EU limit values. This research sets out to evaluate the effectiveness of Local Air Quality Management, as evidenced over the last 14 years, as a means to improve local air quality focusing on annual mean $\mathrm{NO}_{2}$. Previous research has presented the methodology for the sample selection for this study; this paper describes the methodology relating to the resulting six local authority case studies, but presents the results of the trends in $\mathrm{NO}_{2}$ concentrations in the Bristol AQMA as an example, before drawing conclusions and making recommendations for improvements to UK air quality management. Keywords: LAQM, automatic monitoring, local government, $\mathrm{NO}_{2}$, air quality objectives, limit values, GIS.
\end{abstract}

\section{Introduction}

\subsection{Local Air Quality Management}

Since 1997, UK local authorities have been managing the quality of air in their jurisdictions against national health-based objectives for specific pollutants as part of the Local Air Quality Management (LAQM) process, prescribed by the Environment Act (1995) and a suite of national air quality strategy documents (Defra [1, 2]; DETR [3]; DoE [4]) and subsequent air quality regulations. For the 
last 14 years, this LAQM process has involved measurement and reporting to Defra and the Devolved Administrations, known as the Review and Assessment stage, and Air Quality Action Planning to remediate any exceedences of the specified objectives designated as Air Quality Management Areas (AQMAs).

LAQM was developed as a means to assist national government in meeting similar health-based air quality limit values set by the European Commission (EC) (Air Quality Framework Directive 96/62/EC and subsequent daughter directives). LAQM was intended to complement national measures, such as implementation of EU legislation (National Emission Ceiling Directive 2001/81/EC) to reduce emissions from various processes, including traffic. While industrial and domestic sources of emissions have reduced under the implementation of these national measures, traffic has continued to be an increasingly important source of health-damaging pollutants. Consequently, in 93\% of the UK's Zones and Agglomerations, the UK government failed to meet the 2010 deadline for the limit values for nitrogen dioxide $\left(\mathrm{NO}_{2}\right)$, one of the key indicators of traffic pollution and itself a health-damaging pollutant and also a precursor for tropospheric ozone $\left(\mathrm{O}_{3}\right)$, and in February 2014 the European Commission launched legal proceedings against the UK for its failure to cut excessive levels of $\mathrm{NO}_{2}$. The government's approach to meeting the EU Directive 2008/50/EC (which replaced Directive 96/62/EC) has been subject to two recent scrutiny reports from the Environmental Audit Committee (House of Commons Environmental Audit Committee [5]; House of Commons Environmental Audit Committee [6]), which recognised the important role that local authorities have to play in helping to reduce traffic pollution. In 2013, however, Defra issued a consultation on the future of LAQM, proposing a range of options including the removal of the role of local authorities in managing air quality (Defra [7]).

\subsection{Research statement}

This research sets out to evaluate the effectiveness of the local authorities' Air Quality Action Planning, as evidenced over the last 14 years, as a means to improve local air quality and thereby to assist the UK government in meeting the EU annual mean limit value for $\mathrm{NO}_{2}$. This focused perspective does not seek to assess the worth of LAQM in terms of its wider benefits, but concentrates on its key role of reducing local air pollution hotspots with particular reference to the most significant problem faced by national government, the reduction of trafficrelated $\mathrm{NO}_{2}$.

Based on experience to date, the research statement is as follows:

Local Air Quality Action Plans are not successful in terms of reducing local concentrations of $\mathrm{NO}_{2}$ and therefore Local Air Quality Management will not achieve the annual mean UK air quality objective and will therefore not make an effective contribution to meeting the relevant EU limit value.

The methodological approach for this research is summarised in Figure 1, with the subject of this paper focusing on Steps $1 \mathrm{~b}$ and 1c which addresses the first of two research objectives (Objective 1: document the change in the concentration of annual mean nitrogen dioxide from road traffic using 


\section{Step 1 - assess significant changes in road-contribution nitrogen dioxide within} AQMAs against Round 1 baseline

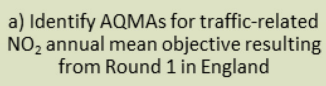

a) Identify AQMAs for traffic-related $\mathrm{NO}_{2}$ annual mean objective resulting from Round 1 in England

b) Establish Round 1 baseline roadcontribution $\mathrm{NO}_{2}$ within AQMAs c) Establish road-contribution $\mathrm{NO}_{2}$ for subsequent years

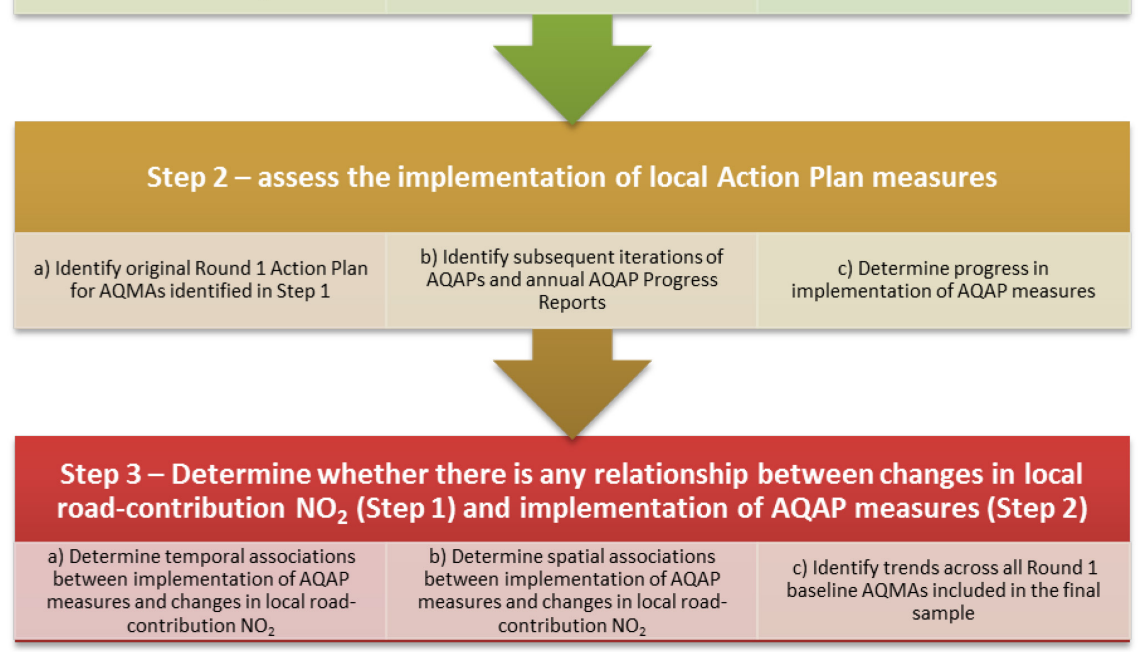

Figure 1: Methodological flow diagram.

continuous monitoring data, in AQMAs declared in Round 1 of Review and Assessment).

\section{Method}

\subsection{Criteria for selecting AQMAs/local authorities}

The methodological approach, as set out in figure 1, was to identify changes in local (road contribution) $\mathrm{NO}_{2}$ over the period of the implementation of Air Quality Action Plans (AQAPs), the implementation of measures in related AQAPs, and to statistically assess any correlative relationship between them. It was therefore necessary to identify those local authorities and respective AQMAs with valid monitoring sites and $\mathrm{NO}_{2}$ annual mean data relevant to their AQMAs, and that have also published AQAPs and subsequent AQAP Progress Reports to enable the implementation of measures to be assessed. A series of criteria were established to identify those local authorities and AQMAs with the information required to apply the methodological approach (figure 2) (Barnes et al. [8]). 


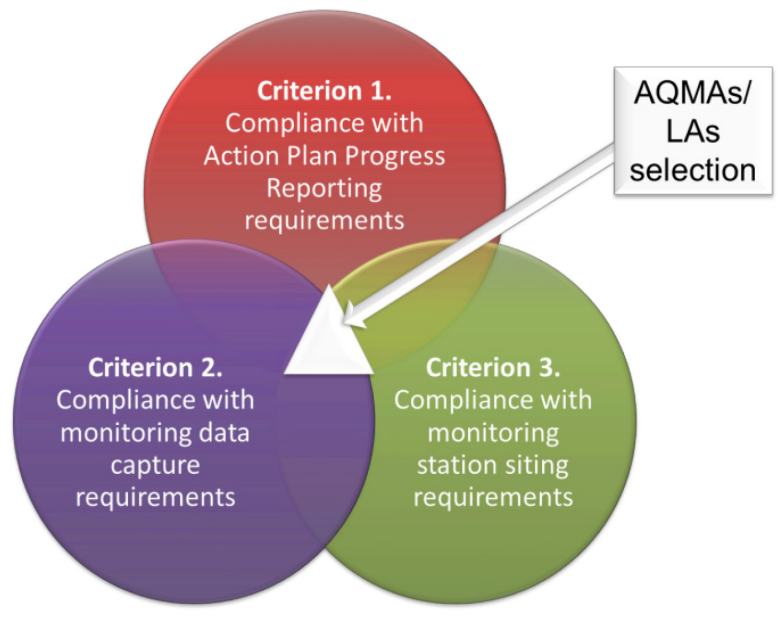

Figure 2: Criteria used to identify local authorities/AQMAs used in this study.

\subsection{Case studies}

The criteria presented in Figure 2 to select those AQMAs for which there were the means to measure the implementation of AQAP actions against local contribution nitrogen dioxide resulted in the identification of eight AQMAs in six local authorities:

- $\quad$ Barnsley Metropolitan Borough Council (Barnsley AQMA);

- $\quad$ Bristol City Council (Bristol AQMA);

- $\quad$ Leicester City Council (Leicester AQMA);

- $\quad$ Oxford City Council (Oxford AQMA);

- Sandwell Metropolitan Borough Council (Great Barr NW, Great Barr South, Great Barr SW);

- $\quad$ City of York Council (York AQMA).

This paper describes the methodology relating to all six of the case studies, but presents the results of the trends in $\mathrm{NO}_{2}$ concentrations in the Bristol AQMA as an example.

\subsection{Monitoring requirements}

Nitrogen dioxide is a health-damaging pollutant, but also acts as a proxy for other traffic-related pollutants and it is easier and cheaper to monitor than $\mathrm{PM}_{10}$. Nitrogen dioxide annual mean concentrations may be obtained from monitoring using automatic monitors, e.g. chemiluminescence analysers, or passive diffusion tubes or modelling. Automatic monitors are more expensive and less straightforward to site than diffusion tubes, but there are higher levels of uncertainty in diffusion tube data $(\sim \pm 25 \%)$ compared to that from automatic 
monitors $(\sim \pm 15 \%)$. Modelling data typically has greater levels of uncertainty than monitoring data due to the numerous estimates and assumptions inherent in the methodology.

Defra and the Devolved Administrations (DAs) have operated a national Automatic Urban and Rural Network (AURN) of analysers since 1987 with a standardised Quality Assurance/Quality Control process (Defra [9]). To minimise the level of uncertainty between data relating to different AQMAs, AURN data were used wherever possible in this study. As fixed monitors, longterm data from these sites are also more likely to be available. Data for AURN sites were obtained from the Air Quality Data Archive (http://ukair.defra.gov.uk/data/).

In order to identify trends in local concentrations of nitrogen dioxide, it was necessary to obtain annual mean concentrations of nitrogen dioxide at nearest roadside and background monitoring sites. Background concentrations are largely unaffected by local measures to improve air quality, but reflect the implementation of national measures, regional climatology and annual meteorological variability in nitrogen dioxide. In order to determine the effect of local traffic measures it was therefore necessary to discount the background concentration and compare only the local source element of the roadside annual mean (Stedman et al. [10]).

\subsection{Monitoring sites and data}

There were 23 Traffic Urban sites (2 AURN and 21 LA) and 9 Background Urban sites (4 AURN and 5 LA) that were representative of the eight AQMAs across six local authorities. Annual mean $\mathrm{NO}_{2}$ concentrations for years with greater than $75 \%$ data capture, as reported in the local authorities' Review and Assessment reports, were recorded from 2004 to 2012. For each AQMA annual mean $\mathrm{NO}_{2}$ concentrations for the representative Traffic Urban and Background Urban sites were matched against each other year-on-year to enable the local contribution $\mathrm{NO}_{2}$ to be calculated on an annual basis. As all sites had been selected based on $75 \%$ data capture across the period 2005-2012, there were at least six years' valid data for each site, however, Traffic Urban and Background Urban sites did not necessarily have corresponding years with valid data. The $75 \%$ data capture across the period ensured there was a maximum of two years without data for each site, and therefore at least four years' matching data between Traffic Urban and Background Urban sites on which to calculate local trends. The inclusion of 2004 data, where available, also contributed to the robustness of the trend calculation. Local contribution $\mathrm{NO}_{2}$ was calculated as the difference between Traffic Urban and Background Urban sites' annual means. Traffic Urban, Background Urban and Local Contribution $\mathrm{NO}_{2}$ annual means were plotted in Excel and with linear regression analysis trend lines of Local Contribution $\mathrm{NO}_{2}$ and Background Urban $\mathrm{NO}_{2}$ over the period, the gradient of the trend line indicating either an upward $(>0.5)$, downward $(>-0.5)$ or static trend $(< \pm 0.5)$. 


\section{Results}

\subsection{Bristol CC (Bristol AQMA)}

As a Unitary Authority, Bristol City Council also operates as a single-tier authority, but has retained links with its former-Avon neighbouring authorities in developing Joint Local Transport Plans. The original AQMA was declared in 2001 and covered the City Centre, including major radial roads, and Avonmouth Docks (M5/M49 junction), though as the Avonmouth section was revoked in 2008 this research has focused on the City Centre. The primary emissions source was cars and taxis, due to their high contribution to traffic volume.

There were two Background Urban sites (Bristol St Paul's (AURN) and Brislington Depot (LA)), and seven Traffic Urban sites (Bristol Old Market (AURN), Newfoundland Way Police Station (LA), Bath Road (LA), Parson Street School (LA), Shiner's Garage (LA), Wells Road (LA) and Rupert Street (LA)) that were considered representative of the Bristol AQMA - Rupert Street, although classified by the local authority as an Urban Centre site, is more characteristic of a Traffic Urban than a Background site (Figure 3).

The local contribution to roadside $\mathrm{NO}_{2}$ was calculated at each Traffic Urban site. The AURN site Bristol St Pauls was only operational from 2007 to 2012, with an average $31 \mu \mathrm{g} / \mathrm{m}^{3} \mathrm{NO}_{2}$ annual mean. The average $\mathrm{NO}_{2}$ annual mean for the Brislington Depot site is $35.5 \mu \mathrm{g} / \mathrm{m}^{3}$. The apparent trend at both sites appears to be relatively static with very little annual variation; the exception being a low of $27 \mu \mathrm{g} / \mathrm{m}^{3}$ in 2007 at Bristol St Pauls causing a slight downward trend at this site. Both sites are approximately $30 \mathrm{~m}$ from the nearest road, though the Brislington Depot site may be more heavily trafficked, which would account for the slightly higher concentrations measured at this location. Both sites are within $5 \mathrm{~km}$ of all other sites and therefore, according to the siting criteria used for selecting monitoring stations (Barnes et al. [8]), may be taken as being representative of background concentrations at all locations. Given the potential for the Brislington Depot site to be affected by local traffic sources and the rigour of AURN site QA/QC and reporting, however, the Bristol St Pauls site was used in the local contribution calculations across all sites to ensure comparability. The gradient of the trendline for this site $(-0.2286)$ indicates a slight decline in background concentrations over the six years (2007-2012 inclusive). This is in contrast to the trend in background concentrations recorded at the Brislington Depot site, which showed a fairly static or slightly upward trend $(\sim 0.15)$.

Figure 4 shows a summary of the trendline gradients of local contribution $\mathrm{NO}_{2}$ at each Traffic Urban site (2004-2012). Most sites showed a decrease in concentrations with Rupert Street and Wells Road showing the greatest reduction $(>-1.5)$. Bath Road, Newfoundland Road Police Station and Parson Street School showed marginal decreases $(<-1)$. Bristol Old Market and Shiner's Garage showed similar magnitude increases. 


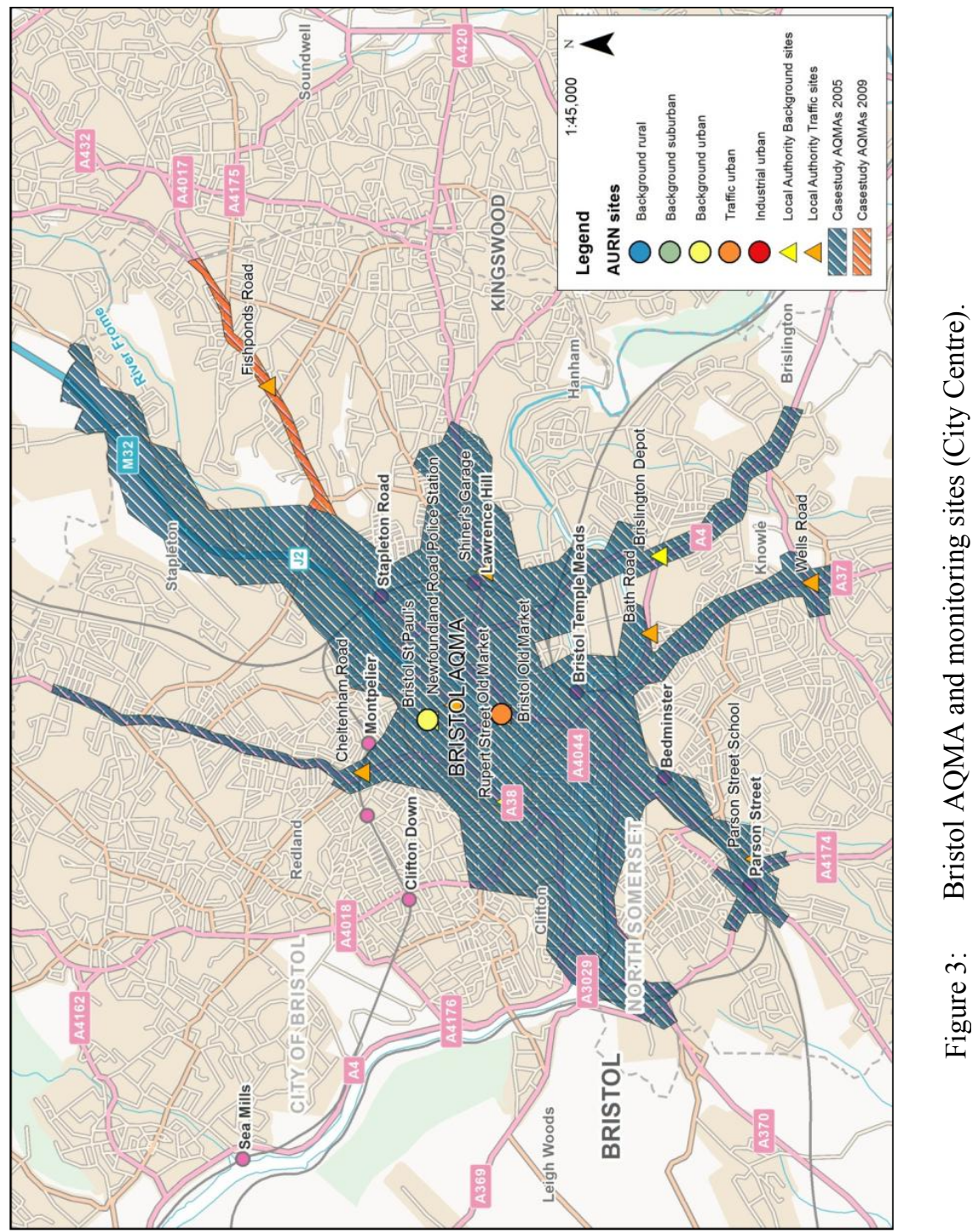




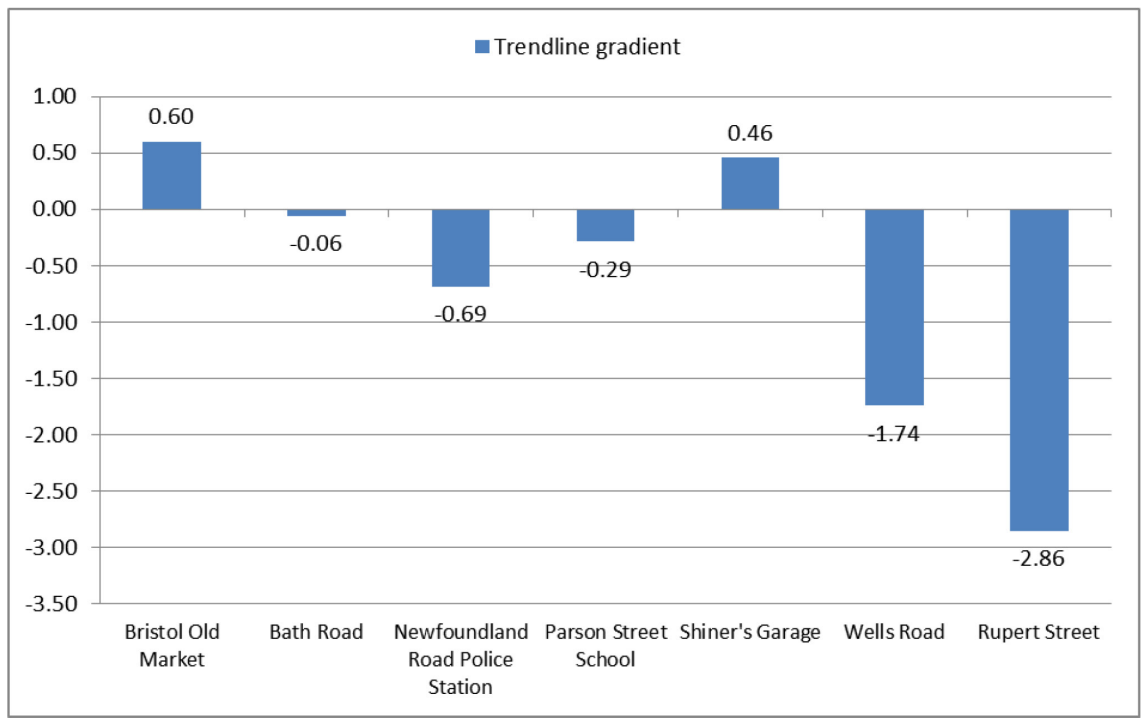

Figure 4: Bristol trendline gradients of local contribution $\mathrm{NO}_{2}$ at each Traffic Urban site (2004-2012).

\section{Discussion}

\subsection{Bristol City Council (Bristol AQMA)}

There were two Background Urban sites, and seven Traffic Urban sites that were within the requisite distances of the Bristol AQMA. To ensure consistency across all sites, only the St Paul's (AURN) Background Urban site was used to calculate the local contribution $\mathrm{NO}_{2}$ at each Traffic Urban site as there was concern that the Brislington Depot site may have been unduly influenced by a nearby heavily-trafficked road.

Bristol Old Market (AURN) did not meet the EU siting criteria as it was situated on a major road junction and so monitoring ceased in January 2013. The Newfoundland Way Police Station site and Bath Road site were installed to measure the impact of specific developments and so may not be best placed to assess the impact of AQAP measures, although Bath Road was representative of traffic flows on the A4 until monitoring ceased here in January 2013. The Shiner's Garage site was specifically installed to assess the impact of the A420 bus showcase route and ceased monitoring in January 2013. Rupert Street was categorized by the local authority as an Urban Centre site (representative of Background Urban concentrations), but it is actually more representative of a Traffic Urban site. This is a case of local authority site type classifications differing, or being less rigorous than EU site type classifications used by the AURN, and hence a source of confusion in identifying appropriate sites on this basis. 
There is a slight downward trend in nitrogen dioxide concentrations at the $\mathrm{St}$ Paul's Background Urban site over the period 2007-2012 (gradient -0.23), although this is largely influenced by low concentrations in 2011 as 2012 concentrations are as high or higher than in preceding years. At the Bristol Old Market site, total $\mathrm{NO}_{2}$ concentrations increased 2004-2010, which is reflected in the slight upward trend in local contribution $\mathrm{NO}_{2}$ at this site during 2007-2010 (gradient 0.60). The Bath Road site has seen a static to slight decrease in total $\mathrm{NO}_{2}$ concentrations 2007-2012 resulting in a marginal downward trend in local $\mathrm{NO}_{2}$ over the same period (gradient -0.06). At Newfoundland Way Police Station total $\mathrm{NO}_{2}$ concentrations between 2005 and 2012 began falling in 2010 resulting in an overall downward trend in local $\mathrm{NO}_{2}$ at this site 2007-2012 (gradient 0.69). Total $\mathrm{NO}_{2}$ concentrations at Parson Street School have remained relatively static 2005-2012 with a slight decrease in 2011-2012. The resulting trend in local $\mathrm{NO}_{2}$ concentrations has been a very slight decrease 2007-2012 (gradient 0.29 ). At Shiner's Garage total $\mathrm{NO}_{2}$ concentrations have remained relatively static 2005-2012 with a very slight upward trend in local $\mathrm{NO}_{2}$ 2007-2012 (gradient 0.46). At Wells Road total $\mathrm{NO}_{2}$ concentrations 2005-2009 were static but have shown a marked decrease 2010-2012 resulting in a downward trend in local $\mathrm{NO}_{2}$ concentrations 2007-2012 (gradient -1.74). At Rupert Street total $\mathrm{NO}_{2}$ was increasing 2004-2008 but has subsequently begun to fall. The trend in local $\mathrm{NO}_{2}$ concentrations at this site has shown the steepest decrease 2007-2012 (gradient -2.86).

In summary, the distribution of Traffic Urban monitoring sites across Bristol City Centre has presented an informative representation of the variability of $\mathrm{NO}_{2}$ concentrations and trends in this urban area. The findings have been conflicting in some cases, with downward trends in concentrations in some areas but not others (e.g. A420 route), suggesting that there may be confounding factors, other than AQAP implementation, affecting these sites - unfortunately, since both the Shiner's Garage and Bristol Old Market sites have since been discontinued, continued assessment of this situation is not possible at these locations.

\section{Conclusion}

With reference to the research question, the key finding from this research is a confirmation of the research statement, i.e. that currently LAQM is not a successful strategy in achieving selected EU limit values. An absence of representatively sited robust monitoring data indicates that, collectively, the means to assess the effectiveness of LAQM in terms of reducing local concentrations of $\mathrm{NO}_{2}$ does not currently exist.

Despite the opportunity that LAQM provided to assist the government with achievement of the EU limit values, the process was never calibrated sufficiently to provide a measureable contribution. There are several factors that have been identified in this research to corroborate this statement, two of which are specific to monitoring data.

Firstly, there are insufficient government monitoring sites available to gauge progress against EU limit values in AQMAs. This research has shown that only 
one AQMA had adequately sited Traffic Urban and Background Urban AURN sites available, and even this Traffic Urban site had been shown not to be compliant with EU siting criteria. The government could have established AURN sites in each AQMA in order to assess changes in concentrations of the key pollutants, e.g. $\mathrm{NO}_{2}$, against which progress in the local AQAPs and national measures may be assessed.

Secondly, local authority monitoring sites are not required to be compliant with EU siting or operational criteria. Many local authorities operate automatic monitoring within their AQMAs and are required to adhere to QA/QC procedures to qualify the use of that data in their LAQM reporting. If siting AURN monitors within all of the AQMAs was not feasible, the government could have ensured that LAQM monitoring QA/QC procedures were in line with those required by the European Commission, thereby increasing the network of reportable monitoring data that could be used to determine progress made on local and national actions within AQMAs.

\subsection{Recommendations for improving the effectiveness of LAQM}

The following recommendations are made for Defra, and the Devolved Administrations of Scotland, Wales and Northern Ireland, to improve the effectiveness of LAQM in assisting with the achievement of the $\mathrm{NO}_{2}$ annual mean EU limit value. They are proposed as solutions to the limitations and obstacles observed in undertaking this research, in order to facilitate a combined effort both nationally and locally to reducing traffic-related nitrogen dioxide concentrations in order to achieve the EU limit value. The current revision of LAQM and the recent changes to the EU AAQD reporting requirements make this an opportune moment to instigate these proposed changes.

\section{Recommendation 1: expand the AURN in association with local authorities to ensure that AQMAs have robust representative monitoring sites}

One of the most significant limitations of LAQM identified in this research was the lack of monitoring sites that were representative of AQMAs. Robust assessment is essential to evaluating the effectiveness of AQAP measures and yet $75 \%$ of the AQMAs that had been declared for $\mathrm{NO}_{2}$ annual mean from Round 1 of Review and Assessment in England had no representative AURN sites. While it is recognised that the requirements of LAQM and UK compliance assessment are different, it is considered that there is scope for consolidating local and national assessment to meet the needs of both. This is one of the key aspects of an overarching recommendation to integrate LAQM with EU compliance assessment. A comprehensive review of all AURN and local authority continuous monitoring sites should be undertaken in order to judiciously maximise their representativeness to AQMAs and EU assessment requirements. A rationalisation of monitoring sites may then be possible with unrepresentative or unnecessary monitors redeployed where gaps are identified. The additional monitors that Defra have recently announced (Connolly and Kent 
[11]) that are to be phased in over the next few years could then help to fill any remaining gaps. As part of the integrated air quality management approach, local authority monitors could also be reported to the European Commission, subject to implementation of Recommendations 2 and 3 (below).

\section{Recommendation 2: ensure that continuous monitoring $\mathrm{QA} / \mathrm{QC}$ is rigorous and that monitors are kept in situ for at least the duration of the exceedence in order to assess trends}

This recommendation applies both to AURN and local authority monitoring sites as part of the integrated air quality management approach. One of the other most significant limitations identified in this research was the lack of monitoring sites with robust data over substantial periods to enable trends to be calculated. Furthermore, discontinuation of monitoring sites that were still reporting exceedences was observed in some case studies, even where there was no apparent reason. It is therefore recommended that rigorous QA/QC is maintained to maximise annual data capture, and that representative monitoring sites are kept in situ at least until concentrations are no longer exceeding in order to assess trends.

\section{Recommendation 3: standardise local authority reporting of site type classifications, location and monitoring data to ensure consistency of data reported to the European Commission}

In undertaking this research, a number of inconsistencies were identified in local authorities' classification of site types, grid referencing and reporting of monitoring data, sometimes in contradiction with AURN sites' data reported by Defra. In order to enable an integrated air quality management approach, in which local authority monitoring data are reported to the European Commission, there needs to be standardisation of these aspects of local authorities' monitoring data reporting.

\section{References}

[1] Defra (2007) The Air Quality Strategy for England, Scotland, Wales and Northern Ireland, 1. Norwich: The Stationery Office.

[2] Defra (2003) The Air Quality Strategy for England, Scotland, Wales and Northern Ireland: addendum. London: Defra.

[3] Department for the Environment, Transport and the Regions (2000) The Air Quality Strategy for England, Scotland, Wales and Northern Ireland. London: DETR.

[4] Department of the Environment (1997) The United Kingdom National Air Quality Strategy. London: DoE.

[5] House of Commons Environmental Audit Committee (2010) Air Quality: Fifth Report of Session 2009-10. London: The Stationery Office. 
[6] House of Commons Environmental Audit Committee (2011) Air Quality: A Follow-Up Report, Ninth Report of Session 2010-12. London: The Stationery Office.

[7] Defra (2013) Local Air Quality Management Consultation on Options to Improve Air Quality Management in England [online].London: Defra. [Accessed 31 July 2013].

[8] Barnes, J. H., Hayes, E. T., Longhurst, J. W. S. (2013). Is Local Air Quality Management a Successful Strategy in Achieving Selected EU Limit Values, Air Pollution XXI, Siena, $5^{\text {th }}$ June 2013.

[9] Defra, A Brief History of $A Q$ Monitoring in the UK. Available from: http://www.airquality.co.uk/monitoring_networks.php?n=history [Accessed 8 August 2010].

[10] Stedman, J., Brookes, D., Kent, A.J., Morris, R.J., Cooke, S.L., Lingard, J.J.N., Rose, R.A., Vincent, K.J., Bust, T.J. and Abbott, J.A. (2013) Technical Report on UK Supplementary Assessment Under the Air Quality Directive (2008/50/EC), the Air Quality Framework Directive (96/62/EC) and Fourth Daughter Directive (2004/107/EC) for 2012 [online]. Report number: ID: Ricardo-AEA/R/3380 Issue 1, Ref: ED46644. Defra.

[11] Connolly, E. and Kent, A. (2013) Air Quality Assessment Regime Review for the Ambient Air Quality Directive 2008/50/EC. London: Defra. 